SILVA, P.S.L.; OLIVEIRA, F.H.T.; SILVA, P.I.B. Efeitos da aplicação de doses de nitrogênio e densidades de plantio sobre os rendimentos de espigas verdes e de grãos de milho. Horticultura Brasileira, Brasília, v. 21, n. 3, p. 452-455, julho-setembro 2003.

\title{
Efeitos da aplicação de doses de nitrogênio e densidades de plantio sobre os rendimentos de espigas verdes e de grãos de milho
}

\author{
Paulo Sérgio L. e Silva; Fábio Henrique T. de Oliveira; Paulo Igor B. e Silva \\ 'ESAM, C. Postal 137, 59625-900 Mossoró-RN; E-mail: paulosergio@esam.br
}

\begin{abstract}
RESUMO
Foram avaliados os efeitos da aplicação de doses de nitrogênio (0; 40; 80 e $\left.120 \mathrm{~kg} \mathrm{~N} \mathrm{ha}^{-1}\right)$ e de densidades de plantio (30; 50 e 70 mil plantas ha $\left.\mathrm{a}^{-1}\right)$ sobre a altura de plantas e inserção de espigas, rendimentos de espigas verdes (grãos com 70 a $80 \%$ de umidade) e de grãos e sobre os componentes da produção de grãos da cultivar de milho Centralmex. O rendimento de espigas verdes foi avaliado pelo número e peso de espigas comercializáveis, empalhadas e despalhadas. Um experimento fatorial foi realizado, sob condições de sequeiro, em Mossoró, RN. Utilizou-se o delineamento de blocos ao acaso com cinco repetições. $\mathrm{O}$ aumento da dose de nitrogênio e a redução da densidade de plantio aumentaram todas as características avaliadas, exceto o peso de 100 grãos, sobre o qual o nitrogênio não teve efeito. Houve efeito da interação doses de nitrogênio $x$ densidades de plantio nos números e pesos de espigas empalhadas e despalhadas e no número de espigas maduras.
\end{abstract}

Palavras-chave: Zea mays L., milho verde, níveis de nitrogênio, espaçamento de plantas.

\begin{abstract}
Effects of nitrogen levels application and planting densities on green ears and grain yield

The effect of nitrogen levels applications $(0 ; 40 ; 80$ and $120 \mathrm{~kg}$ $\left.\mathrm{N} \mathrm{ha}^{-1}\right)$ and planting densities (30; 50 and 70 thousand plants ha $\left.{ }^{-1}\right)$ was evaluated over plant and ear heights, green ear yield (grains with $70-80 \%$ of humidity), grain yield and components of grain production of Centralmex maize cultivar. The experiment was set in a factorial scheme in randomized complete blocks with five replications and carried out under dryland conditions in Mossoró, Rio Grande do Norte, Brazil. Green ears yield was evaluated by number and weight of marketable ears with husk, and number and weight of marketable ears without husk. All evaluated traits increased with increasing nitrogen levels and decreasing planting densities, except 100 grains weight which was not affected by nitrogen levels. An effect of planting densities $\mathrm{x}$ nitrogen levels interaction was observed over number and weight of unhusked ears, number and weight of husked ears, and number of mature ears.
\end{abstract}

Keywords: Zea mays L., green corn ,nitrogen levels, plant spacing.

(Recebido para publicação em 23 de agosto de 2002 e aceito em 25 de março de 2003)

$\mathrm{N}_{\mathrm{b}}$ estado do Rio Grande do Norte, bem como no restante da região Nordeste do Brasil, o milho (Zea mays L.) é cultivado para a produção de espigas verdes ou de grãos, sob condições de sequeiro ou com irrigação. Os grãos das espigas verdes constituem o chamado milho verde, isto é, grãos em estado leitoso, com 70 a $80 \%$ de umidade. O milho verde é produto bastante apreciado pelos nordestinos, sendo inclusive utilizado em pratos típicos da região. Os grãos secos são usados nas alimentações humana e animal. Após a colheita das espigas verdes e secas, a palhada é utilizada na alimentação dos rebanhos do próprio agricultor ou comercializada. Os preços compensadores, especialmente na entressafra, dos três referidos produtos, têm estimulado os agricultores norte-rio-grandenses à adoção de maiores densidades de plantio e maiores doses de fertilizantes, especialmente do nitrogênio, visando a obtenção de maiores rendimentos.
Muitos trabalhos (Bangarwa et al., 1992; Bangarwa et al., 1993; Lencoff \& Loomis, 1994; Misra et al., 1994, Spike \& Tollefson, 1991) mostram a influência benéfica de doses de nitrogênio e de populações de plantas sobre o rendimento de grãos secos de milho. No que se refere a milho verde, apenas um trabalho (Ishimura et al., 1984) foi encontrado na literatura tratando do assunto. Os autores constataram que as doses de adubação não tiveram efeito sobre o número e o peso de espigas verdes por ha. Contudo, a população de 62.500 plantas ha- ${ }^{-1}$ propiciou melhores rendimentos de espigas verdes que as outras duas populações avaliadas (41.667 e 50.000 plantas ha-1).

Estudos sobre doses de nitrogênio e densidades de plantio continuam sendo de interesse dos pesquisadores de milho por duas razões. Em primeiro lugar, determinadas doses de nitrogênio e densidades de plantio podem contribuir para aumentos significativos no rendimento de grãos, como constatado por Cardwell (1992), no período de 1930 a 1979, no Estado de Minnesota, EUA, em que os referidos fatores contribuíram com 19 e $21 \%$, respectivamente, para os acréscimos no rendimento de grãos de milho. Em segundo lugar porque o rendimento de milho, em resposta a esses fatores, depende de influências genotípicas (Shanti et al., 1997; Collaud, 1997; Chandra \& Gautan, 1997) e ambientais (Bondavalli et al., 1970).

O objetivo do presente trabalho foi avaliar os efeitos da aplicação de doses de nitrogênio e de densidades de plantio sobre os rendimentos de espigas verdes e de grãos e outras características da cultivar Centralmex.

\section{MATERIAL E MÉTODOS}

O experimento foi realizado na ESAM, RN, de abril a julho/99. Segundo W.C. Thorthwaite, o clima da região é DdAa, isto é, semi-árido e 
Tabela 1. Efeitos da aplicação de doses de nitrogênio e da densidade de plantio sobre as alturas da planta e de inserção da espiga, números de espigas verdes comercializáveis, empalhadas e despalhadas, pesos de espigas verdes comercializáveis, empalhadas e despalhadas, rendimento de grãos, número de espigas maduras, número de grãos espiga- ${ }^{-1}$ e peso de 100 grãos da cultivar de milho Centralmex. Mossoró, ESAM, 1999.

\begin{tabular}{|c|c|c|}
\hline Características & $\begin{array}{l}\text { Efeitos de doses de } N(0,40,80 \text { e } 120 \mathrm{~kg} \mathrm{~N} \text { ha-1) e da } \\
\text { densidade de plantio (D) }(30,50 \text { e } 70 \text { mil plantas ha- } 1)\end{array}$ & $R^{2}$ \\
\hline$\overline{\text { Altura da planta }(\mathrm{cm})}$ & $Y=198,3+0,6654^{* *} \mathrm{~N}-0,0003375^{* *} \mathrm{D}$ & 0,93 \\
\hline Altura de inserção da espiga $(\mathrm{cm})$ & $Y=103,5+0,4750^{* *} N-0,0001938^{* *} D$ & 0,96 \\
\hline Número de espigas empalhadas ha-1 & $Y=36664-118,971^{*} N-0,5023^{* *} D+0,006672^{* *} N \cdot D$ & 0,91 \\
\hline Número de espigas despalhadas ha-1 & $Y=29218-21,1336 n s N-0,4412^{* *} D+0,004232^{* *} N . D$ & 0,91 \\
\hline Peso espigas empalhadas $\left(\mathrm{kg} \mathrm{ha}^{-1}\right)$ & $Y=6833+17,6595^{* *} \mathrm{~N}-0,09912^{* *} \mathrm{D}+0,0006211^{* *} \mathrm{~N} . \mathrm{D}$ & 0,90 \\
\hline Peso espigas despalhadas $\left(\mathrm{kg} \mathrm{ha}^{-1}\right)$ & $Y=3367+16,2622^{*} N-0,05249^{* *} D+0,0002244^{*} N . D$ & 0,90 \\
\hline Rendimento de grãos (kg ha-1) & $Y=2204,9+20,6908^{* *} N-0,02181^{* *} D$ & 0,94 \\
\hline Número de espigas maduras ha-1 & $Y=25776-50,6189 n s N-0,1605^{*} D+0,004729^{* *} N . D$ & 0,94 \\
\hline Número de grãos espiga ${ }^{-1}$ & $Y=344,4+1,1667^{* *} N-0,002625^{* *} D$ & 0,92 \\
\hline Peso de 100 grãos (g) & $Y=32,88+0,004083 n s N-0,00007875^{* *} D$ & 0,70 \\
\hline
\end{tabular}

${ }^{\mathrm{n}}$ não-significativo. ${ }^{*}$ Significativo a $5 \%$ de probabilidade pelo teste $\mathrm{t} .{ }^{* *}$ Significativo a $1 \%$ de probabilidade pelo teste $\mathrm{t}$

megatérmico. A análise do solo resultou: $\mathrm{pH}=6,4 ; \mathrm{P}=16 \mathrm{cmol}_{\mathrm{c}} \mathrm{cm}^{-3} ; \mathrm{K}=78$ $\mathrm{cmol}_{\mathrm{c}} \mathrm{cm}^{-3} ; \mathrm{Ca}^{2+}=3,0 \mathrm{cmol}_{\mathrm{c}} \mathrm{cm}^{-3} ; \mathrm{Mg}=$ $1,3 \mathrm{cmol}_{\mathrm{c}} \mathrm{cm}^{-3} \mathrm{eAl}^{3+=} 0,0 \mathrm{cmol}_{\mathrm{c}} \mathrm{cm}^{-3} ; \mathrm{MO}$ $=1,80 \mathrm{~g} \mathrm{~kg}^{-1}$.

O solo foi preparado com duas gradagens. A semeadura foi feita em $7 /$ $4 / 99$, usando-se quatro sementes por cova da cultivar Centralmex, uma variedade de polinização livre, de porte alto, tardia e de grãos amarelos. Foram avaliadas três densidades de plantio (30; 50 e 70 mil plantas ha-1 $)$ e quatro doses de ni-

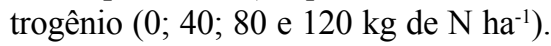
As densidades de plantio foram obtidas mantendo-se fixo o espaçamento $(1,0 \mathrm{~m})$ entre fileiras de plantas e variando-se o número de plantas na linha de plantio. Um terço do nitrogênio (sulfato de amônio), além de $60 \mathrm{~kg}$ de $\mathrm{P}_{2} \mathrm{O}_{5}$ ha $^{-1}$ (superfosfato simples) e $30 \mathrm{~kg}$ de $\mathrm{K}_{2} \mathrm{O}$ $\mathrm{ha}^{-1}$ (cloreto de potássio) foram aplicados como adubação de plantio, em sulcos localizados ao lado e abaixo dos sul$\cos$ de semeadura. O restante do nitrogênio foi aplicado em cobertura, aos 36 dias após o plantio. Utilizou-se o delineamento de blocos ao acaso em esquema fatorial completo com cinco repetições e parcelas constituídas por quatro fileiras com 6,0 m de comprimento. Considerou-se como área útil a ocupada pelas duas fileiras centrais, eliminando-se as plantas de uma cova em cada extremidade.

O controle da lagarta-do-cartucho (Spodoptera frugiperda J.E. Smith) foi feito com três pulverizações de deltamethrin $\left(250 \mathrm{ml} \mathrm{ha}^{-1}\right)$, em intervalos de sete dias, sendo a primeira realizada aos sete dias após a semeadura. As invasoras foram controladas por duas capinas, realizadas aos 21 e 41 dias após a semeadura. Aos 26 dias após a semeadura realizou-se o desbaste, deixandose as duas plantas mais vigorosas/cova.

Foram avaliadas as alturas das plantas e de inserção da espiga (em dez plantas tomadas ao acaso na área útil, por ocasião da colheita das espigas maduras), o rendimento de milho verde, o rendimento de grãos e seus componentes. O rendimento de espigas verdes foi avaliado em uma das fileiras úteis, tomada ao acaso, e o rendimento de grãos, na outra fileira útil. A altura da planta foi medida do nível do solo ao ponto de inserção da lâmina foliar mais alta. A altura de inserção da espiga foi obtida medindo-se a distância do nível do solo ao nó de inserção da primeira espiga. As espigas verdes foram colhidas em três etapas, à medida que os grãos atingiam o chamado "ponto de milho verde", no período de 72 a 82 dias após a semeadura. As espigas secas foram colhidas aos 110 dias após a semeadura. O rendimento de milho verde foi avaliado pelo número e peso de espigas verdes comercializáveis, empalhadas e despalhadas. Como espigas verdes empalhadas comercializáveis foram consideradas aquelas com aparência adequada à comercialização, isto é, sem evidências aparentes do ataque de pragas e com comprimento superior a 23 $\mathrm{cm}$. Como espigas despalhadas comercializáveis foram consideradas aquelas com aparência adequada à comercialização, isto é, bem granadas, não atacadas por pragas e com comprimento superior a $18 \mathrm{~cm}$. O rendimento de grãos foi corrigido para um teor de umidade igual a $15,5 \%$. O número de espigas/ha foi estimado com base nas espigas produzidas em uma fileira útil, o número de grãos/espiga foi estimado contando-se os grãos de cinco espigas, tomadas aleatoriamente entre as espigas colhidas na fileira útil, e o peso de 100 grãos, em cinco amostras de 100 grãos. As análises estatísticas foram feitas de acordo com as recomendações de Gomes (1992) e StatSoft (1995).

\section{RESULTADOS E DISCUSSÃO}

Os efeitos das densidades de plantio (D) e da aplicação das doses de nitrogênio (N) sobre as alturas da planta e de inserção da espiga foram muito similares (Tabela 1). Nas duas características os efeitos dos dois grupos de tratamentos foram independentes, isto é, não houve efeito da interação $\mathrm{D} \times \mathrm{N}$. Em cada dose de N, a resposta da cultivar, em termos das duas características, ao aumento da densidade de plantio, foi linear e negativa, isto é, a resposta foi 
descrita por equações do tipo $\mathrm{y}=\mathrm{a}-$ bx. Bangarwa et al. (1993) verificaram que a altura da planta não foi alterada pela densidade de plantio, enquanto Merotto et al. (1997) constataram aumento da altura da planta com o aumento da densidade de plantio. As discordâncias quanto aos efeitos das densidades de plantio na altura da planta devem-se, certamente, às diferentes densidades de plantio avaliadas pelos diferentes autores, dentre outros fatores ambientais, mas devem-se também às características das cultivares avaliadas. Begna et al. (1997) demonstraram que as cultivares não-folhosas, com menor estatura, suportaram melhor maiores densidades. A influência da folhosidade na tolerância a altas densidades também tem sido verificada por outros autores (Sangoi \& Salvador, 1998). Por outro lado, a resposta das duas características às doses de nitrogênio, em cada densidade de plantio, foi positiva e descrita por equações do tipo $\mathrm{y}=\mathrm{a}+\mathrm{bx}-\mathrm{cx}^{2}$. Nas densidades testadas, os valores máximos dos dois caracteres seriam obtidos fora do intervalo das doses de nitrogênio avaliadas (em torno de 130 $\mathrm{kg}$ de $\mathrm{N} \mathrm{ha}^{-1}$, na altura da planta, e 142 $\mathrm{kg}$ de $\mathrm{N} \mathrm{ha}^{-1}$, na altura de inserção da espiga). Nestes casos, o que deve acontecer é que até determinadas doses de nitrogênio a planta continua a crescer. Depois que tais doses são atingidas, o auto-sombreamento das plantas, bem como o sombreamento mútuo entre plantas deve contribuir para a redução do crescimento destas plantas.

No número de espigas verdes empalhadas e no número de espigas despalhadas (Tabela 1), comercializáveis, por hectare, houve efeito de densidades (D), de doses de nitrogênio $(\mathrm{N})$ e da interação $\mathrm{D}$ x $\mathrm{N}$ e tais efeitos foram semelhantes. No número de espigas empalhadas, numa mesma dose de nitrogênio, os efeitos das densidades de plantio foram lineares, mas negativos na ausência da aplicação de nitrogênio ( $\mathrm{y}=36664-0,5023 \mathrm{D})$ ou com a aplicação de apenas $40 \mathrm{~kg}$ de $\mathrm{N} \mathrm{ha}^{-1}$ ( $\left.\mathrm{y}=31905-0,4956 \mathrm{D}\right)$. Mas positivos nas outras duas doses $(y=27146$ $+0,0315$ e y $=22387+0,2953 \mathrm{D}, \mathrm{com}$ 80 e $120 \mathrm{~kg}$ de $\mathrm{N} \mathrm{ha}^{-1}$, respectivamente). No caso das espigas despalhadas, os efeitos das densidades de plantio, numa mesma dose de nitrogênio, somente foram positivos na dose mais elevada. Nas outras doses eles foram negativos. Em cada densidade de plantio, a resposta ao nitrogênio foi linear e positiva, mas os acréscimos no número de espigas empalhadas ou despalhadas, por quilo de nitrogênio aplicado, foram maiores à medida que se aumentou a densidade de plantio.

Quanto aos pesos de espigas comercializáveis, empalhadas ou despalhadas (Tabela 1), também houve efeito de D, $\mathrm{N}$ e $\mathrm{D} \times \mathrm{N}$. Em cada dose do fertilizante, o número de espigas empalhadas ou despalhadas decresceu linearmente, à medida que foram aumentadas as densidades de plantio, mas os decréscimos foram diferentes. Os valores de b foram 0,$09 ; 0,07 ; 0,05 \mathrm{e}$ $0,02 \mathrm{~kg} \mathrm{ha}^{-1}$ para as doses de 0; 40; $80 \mathrm{e}$ $120 \mathrm{~kg} \mathrm{ha}^{-1}$, respectivamente, no caso do peso de espigas empalhadas. No caso de espigas despalhadas, os valores respectivos de $b$ foram 0,$05 ; 0,04 ; 0,03$ e $0,02 \mathrm{~kg} \mathrm{ha}^{-1}$. Em cada densidade de plantio, a resposta ao nitrogênio foi linear e positiva, quanto ao peso de espigas, empalhadas ou despalhadas, mas os acréscimos foram diferentes. No peso de espigas empalhadas, os valores de b, nas populações de 30; 50 e 70 mil plantas $\mathrm{ha}^{-1}$, foram 36,$3 ; 48,7$ e $61,1 \mathrm{~kg} \mathrm{ha}^{-1}$, respectivamente. No peso de espigas despalhadas, os valores respectivos foram de 23,0; 27,5 e 32,0 $\mathrm{kg} \mathrm{ha}^{-1}$.

No rendimento de grãos houve efeito de densidades de plantio (D) e de doses de nitrogênio $(\mathrm{N})$, mas não da interação D x N (Tabela 1). Em cada dose de nitrogênio, o aumento da densidade de plantio diminuiu o rendimento de grãos de modo linear. Em cada densidade de plantio, o nitrogênio aumentou o rendimento de grãos, linearmente.

No que se refere ao número de espigas maduras (Tabela 1) houve efeito de $\mathrm{D}, \mathrm{N}$ e $\mathrm{D} \times \mathrm{N}$. A resposta da cultivar Centralmex, quanto a esta característica foi bem semelhante à resposta quanto ao número de espigas empalhadas comercializáveis. Isto é, nas duas menores doses de nitrogênio, a resposta ao aumento da densidade de plantio foi linear e negativa, mas linear e positiva nas outras duas doses (os valores de b foram -0,16; -0,03;0,22 e 0,41 espigas ha ${ }^{-1}$, respectivamente). Em outras palavras, o aumento do número de espigas maduras, para cada acréscimo na densidade, aumentou à medida que se aumentou a dose de nitrogênio. Por outro lado, em cada densidade de plantio, a resposta foi linear e positiva ao nitrogênio, mas os acréscimos foram maiores, com o aumento da densidade (os valores de b para as densidades de 30; 50 e 70 mil plantas $\mathrm{ha}^{-1}$ foram iguais a 91,$3 ; 185,8$ e 280,4 espigas $\mathrm{ha}^{-1}$, respectivamente).

No número de grãos/espiga, houve efeito apenas de densidades de plantio e de doses de nitrogênio (Tabela 1). O número de grãos/espiga aumentou linearmente com doses crescentes de nitrogênio e diminuiu linearmente com o aumento da densidade de plantio. Lencoff \& Loomis (1994) verificaram que a deficiência de nitrogênio reduziu o número de grãos/espiga do milho devido a uma redução na emergência nos estilo-estigmas, em conseqüência da redução das divisões celulares.

O nitrogênio não teve efeito no peso de 100 grãos, mas o aumento na densidade de plantio reduziu, linearmente, esta característica (Tabela 1).

Constata-se que em geral a maior densidade de plantio reduz o crescimento da planta (neste trabalho avaliado pelas alturas da planta e de inserção da espiga), o número (nas duas menores doses de nitrogênio) e o peso de espigas verdes e o rendimento de grãos (Tabela 1). Constata-se ainda que os decréscimos no rendimento de grãos são devidos a decréscimos nos três componentes da produção (número de espigas/ha, número de grãos/espiga e peso de 100 grãos). As reduções são devidas provavelmente a uma maior competição entre plantas, à medida que se eleva o número de plantas por unidade de área. Verifica-se também que a maior dose de nitrogênio aumenta o crescimento da planta e os rendimentos de espigas verdes e de grãos. Neste caso, o rendimento de grãos é aumentado apenas devido aos aumentos no número de espigas ha ${ }^{-1}$ e no número de grãos/espiga, desde que o nitrogênio não teve efeito no peso de 100 grãos. Em algumas características como nos números de espigas ha-1, 
empalhadas, despalhadas e maduras, o efeito negativo causado pelo aumento da densidade de plantio tende a ser parcialmente anulado pelo nitrogênio. Uma maior disponibilidade de nitrogênio para as plantas explicaria os efeitos positivos do nitrogênio para a quase totalidade das características avaliadas no presente trabalho. Efeitos positivos do nitrogênio foram observados nos rendimentos de espigas de milho doce (Mullins et al., 1999) espigas verdes de milho comum (Monteiro et al., 1989; Silva et al., 2000), no chamado "baby corn" ou minimilho (espigas colhidas, em geral, imediatamente após a emergência dos estilo-estigmas) (Sahoo et al., 1999; Thakur et al., 1998) e no rendimento de grãos (Lencoff \& Loomis, 1994).

Conclui-se que o aumento da dose de nitrogênio e a redução da densidade de plantio aumentaram as alturas da planta e de inserção da espiga o número e o peso de espigas comercializáveis, empalhadas e despalhadas, o rendimento de grãos e seus componentes, exceto o peso de 100 grãos, sobre o qual o nitrogênio não teve efeito.

\section{LITERATURA CITADA}

BANGARWA, A.S.; SING, K.P.; KAIRON, M.S Effect of plant density and $\mathrm{N}$ fertilization on grain yield and $\mathrm{N}$ use efficiency in winter maize ( $\mathrm{Zea}$ mays L.). Haryana Journal of Agronomy, v. 8, n. 2, p. 88-92, 1992.
BANGARWA, A.S.; KAIRON, M.S.; MOR, B.S. Effect of plant density and levels of nitrogen on the growth analysis of winter maize (Zea mays L.). Crop Research, v. 6, n. 1, p. 5-16, 1993. BEGNA, S.H.; HAMILTON, R.I.; DWYER, L.M.; STEWART, D.W.; SMITH, D.L. Effects of population density and planting pattern on the yield and yield components of leafy reducedstature maize in a short-season area. Journal of Agronomy and Crop Science, v. 179, n. 1, p. 9-17, 1997.

BONDAVALLI, B.; COLYER, D.; KROTH, E.M. Effects of weather, nitrogen and population on corn yield response. Agronomy Journal, v. 62, n. 5, p. 669-672, 1970 .

CARDWELL, V.B. Fifty years of Minnesota corn production: sources of yield increase. Agronomy Journal, v. 74, n. 6, p. 984-995, 1992.

CHANDRA, D.; GAUTAN, R.C. Performance of maize varieties at varying plant densities. Annals of Agricultural Research, v. 18, n. 3, p. 375-376, 1997.

COLLAUD, J.F. Semis de maiis à hautes densités. Revue Suisse d'Agriculture, v. 29, n. 4, p. 195 198, 1997.

GOMES, J.M. SAEG. Viçosa, UFV, Central de Processamento de Dados, 1992.

ISHIMURA, I.; SAWAZAKI, E.; IGUE, T.; NODA, M. Práticas culturais na produtividade de milho verde. Pesquisa Agropecuária Brasileira, Brasília, v. 19, n. 2 p. 201-206, 1984.

LENCOFF, J.H.; LOOMIS, R.S. Nitrogen and density influences on silk emergence, endosperm development, and grain yield in maize (Zea mays L.). Field Crop Research, v. 38, n. 1, p. 63-72, 1994.

MEROTTO JÚNIOR, A.; ALMEIDA, M.L.; FUCHS, O. Aumento no rendimento de grãos de milho através do aumento da população de plantas. Ciência Rural, v. 27, n. 4, p. 549-554, 1997. MISRA, B.N.; YADAV, R.S.; RAJPUT, A.L.; PANDEY, S.M. Effect of plant geometry and nitrogen application on yield and quality of winter maize. Indian Journal of Agronomy, v. 39, n. 3, p. 468-469, 1994.
MONTEIRO, M.A.R.; COSTA, E.F.; GHEIY, H.R.; PINTO, J.M. Níveis de nitrogênio e lâminas de irrigação no rendimento de milho verde. Pesquisa Agropecuária Brasileira, Brasília, v. 24, n. 6, p. 741-749, 1989.

MULLINS, C.A.; STRAW, R.A.; PITT, B.; ONKS, D.O.; MULLEN, M.D.; REYNOLDS, J.; KIRCHNER, M. Response of selected sweet corn cultivars to nitrogen fertilization. HortTechnology, Alexandria, v. 9, n. 1, p. 32-35,1999.

SAHOO, S.C.; PANDA, M.M. Effect of level of nitrogen and plant population on yield of baby corn (Zea mays L.). Indian Journal of Agricultural Sciences, v. 69, n. 2, p. 157-158, 1999.

SANGOI, L.; SALVADOR, R.J. Influência da altura da planta e do número de folhas sobre a produção do milho em altas densidades de plantio. Pesquisa Agropecuária Brasileira, Brasília, v. 33, n. 3, p. 297-306, 1998.

SHANTI, K.; RAO, V.P.; REDDY, M.R.; REDDY, M.S.; SARMA, P.S. Response of maize (Zea mays L.) hybrid and composite to different levels of nitrogen. Indian Journal of Agricultural Sciences, v. 67, n. 9, p. 424-425, 1997.

SILVA, P.S.L.; DINIZ FILHO, E.T.; GRANJEIRO, L.C.; DUARTE, S.R. Efeitos de níveis de nitrogênio e da aplicação de deltametrina sobre os rendimentos de espigas verdes e de grãos de milho. Revista Ceres, Viçosa, v. 47, n. 269, p. 75-87, 2000.

SPIKE, B.P.; TOLLEFSON, J.J. Response of western rootworm infested corn to nitrogen fertilization and plant density. Crop Science, v. 31, n. 3, p. 776-785, 1991.

STATSOFT. Statistica for Windows: computer manual program. Tulsa, 1995.

THAKUR, D.R.; PRAKASH, O.M.; KHARWARA, P.C.; BHALLA, S.K. Effect of nitrogen and plant spacing on yield, nitrogen uptake and economics in baby corn (Zea mays L.). Indian Journal of Agronomy, v. 43, n. 4, p. 668671, 1998. 